\section{ComuniCode: do jornalismo} multimídia hiperlocal à esfera pública internacional

\author{
ComuniCode: hyperlocal \\ multimedia journalism of the \\ international public sphere
}

Zanei Ramos Barcellos ${ }^{[a]}$, Gabriel Alexandre Bozza ${ }^{[b]}$

\section{Resumo}

Este trabalho discute teoricamente a possibilidade do estabelecimento da esfera pública internacional no ciberespaço com o enfraquecimento do Estado-Nação e fortalecimento do poder decisório local e da cidadania, ao mesmo tempo em que mostra o jornalismo em constante reconfiguração para apresentar notícias segmentadas voltadas ao público (hiper)local, em tempo real, distribuídas pela rede mundial de computadores ubíqua e recebidas pelos cidadãos do mundo em seus aparatos móveis, que replicam e interferem na sua produção e viram emissores de comunicação em massa. Assim apresentamos a
Jornalista, doutorando em Gestão Urbana pela Pontíficia Universidade Católica do Paraná (PUCPR), Curitiba, PR-Brasil, e-mail: zanei.barcellos@gmail.com

[b] Jornalista, mestrando em Comunicação pela Universidade Federal do Paraná (UFPR), Curitiba, PR- Brasil, e-mail: gabrielbozz@gmail.com
Palavras-chave: Esfera pública internacional. Cidade. Jornalismo hiperlocal. Mobilidade. QR Code. 
experiência laboratorial de um produto jornalístico hiperlocal distribuído por QR Code, o ComuniCode, pela turma do terceiro ano de Jornalismo da PUCPR, no segundo semestre de 2011. Os alunos acharam uma forma de utilizar o código em produto jornalístico com a criação de um jornal digital multimídia hiperlocal, com distribuição via QR Code com leitura e acessibilidade por mobiles, como em smarthphones $3 \mathrm{G}$.

\begin{abstract}
This paper discusses theoretically the possibility of the establishment of the international public sphere in cyberspace with the weakening of the nation state and strengthening of decision-making and local citizenship, while showing journalism in constant reconfiguration to present news targeted public-facing (hyper)local realtime, distributed by the world Wide Web and ubiquitous received by the citizens of the world on their mobile devices, which replicate and interfere in its production and saw emitting mass communication. Thus we present a laboratory experiment of a hyperlocal news product distributed by QR Code, the ComuniCode, the class of the third year of Journalism PUCPR in the second half of 2011. Students found a way to use the code in journalistic product with the creation of a digital newspaper hyperlocal media, with distribution via $Q R$ Code with reading and accessibility for mobiles, as in $3 G$ smartphones.
\end{abstract}

Keywords: International public sphere. City. Hyperlocal journalism. Mobility. QR Code.

\section{Introdução}

A difusão das plataformas móveis, tais como tablets, notebooks, aparelhos celulares, como os popularizados smartphones, com recursos técnicos avançados, e a tecnologia $3 \mathrm{G}$ que permite o acesso em banda larga, tem obrigado as empresas jornalísticas a segmentar seus conteúdos em formatos capazes de serem acessados por esses aparelhos e a distribuí-los em tempo real para receptores que precisam de informação 
imediata. Dados da pesquisa TIC 2010 sobre o uso das tecnologias de informação e comunicação no Brasil, do Centro de Estudos sobre as Tecnologias da Informação e da Comunicação (CETIC), em 2010, apontam que $35 \%$ dos domicílios brasileiros possuem computador, sendo que $27 \%$ desses têm acesso à internet. Já a penetração dos notebooks nos domicílios brasileiros aumentou 60\% no comparativo 2009-2010, sendo acompanhado por um crescimento vertiginoso na classe $C$ e contínuo domínio das classes A e B. Apesar do crescimento mais modesto da telefonia móvel, os aparelhos celulares estão presentes em $84 \%$ das residências no Brasil (92\% pré-pagos), com aumento de $6 \%$ em 2010, em comparação com o mesmo período de 2009 , sendo que $79 \%$ utilizaram o celular pelo menos uma vez nos últimos três meses. A internet móvel manteve-se estabilizada em razão dos altos custos dos serviços de telefonia móvel no Brasil, colocando o país em 121ạ posição no ranking da International Telecommunications Union (ITU), em 2010.

O imediatismo e a mobilidade necessárias a notícia associados à possibilidade de sua multiplicação com auxílio do cidadão/leitor/receptor/ multiplicador via redes sociotécnicas e aparatos móveis (mobiles) atualmente podem interferir sutil ou bruscamente no cotidiano dos países, regiões e cidades. Isso porque são capazes de desencadear virtual e rapidamente manifestações políticas presenciais, promover happenings culturais localizados, levar multidões a centros de consumo e até a revoluções geradas por qualquer um a qualquer momento e de qualquer lugar; isso tudo com suas consequências imediatas nos serviços públicos de trânsito, segurança, saúde e outros. As novas mídias redesenham os espaços urbanos, interferem na demanda do transporte público e deixam mais complexas as redes que permeiam as cidades. As novas configurações dessas cidades já não coincidem com seus territórios, as espraiando pelo mundo; esses "territórios virtuais" abrangem qualquer lugar onde estejam seus cidadãos conectados, e criam uma esfera pública local-internacional, onde quer que assuntos voltados à sua cidadania sejam discutidos, até mesmo por "cidadãos" que nunca estiveram ou estarão fisicamente em seus territórios. O mesmo se dá com os veículos jornalísticos digitais, que não mais se restringem geograficamente e perpassam quaisquer fronteiras, capacitando até os veículos locais e hiperlocais a atingirem qualquer ponto do planeta.

Sobre as mídias digitais, cabe salientar que, quanto mais voltadas para o noticiário local, de uma forma geral, mais interesse despertam no receptor. Isso tem levado os veículos de comunicação a investirem mais nesse tipo de noticiário, chegando ao extremo do jornalismo 
hiperlocalizado. Quebrou-se assim o paradigma, aceito quando a internet começou a ser usada como meio de distribuição de notícias, de que os grandes portais nacionais e internacionais abarcariam todo o noticiário em detrimento dos veículos regionais e locais.

Este estudo pretende analisar teoricamente as possibilidades de uma esfera pública internacionalizada e suas conexões/implicações no local e no hiperlocal diante das novas possibilidades mediático-comunicacionais proporcionadas pela rede mundial de computadores. Igualmente, pretende apresentar uma experiência de jornalismo digital multimídia hiperlocalizado para aparatos móveis, ou mobiles, utilizando-se do QR Code como forma de distribuição. Essa experiência foi realizada no segundo semestre de 2011 por acadêmicos do 3o ano de Jornalismo (noturno) da Pontifícia Universidade Católica do Paraná (PUCPR).

\section{Espaço público virtual, internacional e local}

O termo "redes sociotécnicas" na acepção de Egler (2007, p. 10) denota espaço virtual "de todos para todos", por viabilizar a qualquer dos seus integrantes conexão imediata a qualquer outro ou a banco de dados, de onde quer que esteja. As redes sociotécnicas são possíveis graças à plataforma proporcionada pela rede mundial de computadores e são potencializadas pela presença ubíqua das redes wireless nos ambientes urbanos, públicos ou não.

Para Kauchakje et al. (2006, p. 6), as redes sociotécnicas constituem uma organização entre agentes sociais que se utilizam de linguagem codificada cuja comunicação é mediada por instrumentos tecnológicos "para que os laços de relacionamentos entre emissores e receptores se tornem efetivos". Na visão desses autores, não se trata apenas de redes sociais utilizando-se de um suporte técnico, mas sim da tecnologia estimulando, mantendo e ampliando o estabelecimento das redes sociais. Da mesma forma, para eles, as redes sociais que se utilizam de suportes digitais facilitam o estabelecimento de uma espécie de mediação entre entidades governamentais, empresas privadas e cidadãos comuns, "possibilitando a unificação da esfera pública com a esfera privada" (KAUCHAKJE et al., 2006, p. 10).

Como se percebe, a possibilidade da unificação, ou encontro das esferas públicas e privadas em espaço virtual, aventada por Kauchakje et al. (2006), devido à não existência de fronteiras para a rede mundial de computadores, denota também a existência de espaço político no 
ciberespaço, que extrapola as fronteiras das cidades, Estados e Nações. Trata-se de uma esfera pública internacional, não sujeita a qualquer poder específico, mas moldada por um amálgama de relacionamentos disformes entre Estados, atores globais não governamentais (negócios, religiões, criadores de cultura, intelectuais públicos, global cosmopolitans), que estariam formando uma governança internacional, não sujeita a poderes efetivos formalizados, mas obediente aos princípios atávicos da democracia (CASTELLS, 2008). Seguindo seu raciocínio, a globalização seria processo formado por um sistema social capaz de trabalhar de forma unificada, mas em escala planetária, em tempo real ou escolhido. No entanto, essa capacidade estaria vinculada a três tipos de capacidade: tecnológica (novas tecnologias comunicacionais e informacionais que conectam de forma seletiva qualquer indivíduo do planeta); institucional (relacionada às desregulamentações e afrouxamento de procedimentos de Estado); e organizacional (relacionada à habilidade de utilização da rede de forma interativa, flexível, sem fronteiras, para qualquer atividade e em qualquer domínio). "Nem tudo ou todos são globalizados, mas a rede mundial que estrutura o planeta afeta a tudo e a todos" (CASTELLS, 2008, p. 81).

Haja vista que alguns assuntos afetam a humanidade como um todo como, por exemplo, meio ambiente (aquecimento global), desenvolvimento sustentável, direitos humanos, armas de destruição em massa, terrorismo e mercado financeiro - , não se estranha o fato de a discussão se dar em termos mundiais e amplamente aberta a todos. $\mathrm{O}$ debate se dá no ciberespaço, ou, mais especificamente, em um espaço público virtual mundial, de certa forma distanciado das esferas onde esses assuntos são administrados - no Estado-Nação, nas regiões e no espaço urbano, os quais vivenciam crises de diferentes ordens: de eficiência, legitimidade (a ação democrática do cidadão resume-se ao voto, a ação política se dá fora das entidades políticas, e a imprensa está afastada de seu verdadeiro papel na esfera pública), identidade (cidadãos mundiais não reconhecem nas ações governamentais nacionais), e igualdade (as desregulamentações agem contra o estado do bem-estar social, agravando diferenças sociais).

Essa situação demonstra o quanto a vida do cidadão e seus governos são afetados por questões globais; também evidencia o enfraquecimento das entidades tradicionais como sindicatos, partidos, associações civis e religiões, cuja ação está mais afeita às questões locais. Por outro lado, os grandes grupos econômicos interferem e dominam cada vez mais os grandes partidos e, assim, as diferentes instâncias governamentais. 
O abandono das entidades políticas tradicionais e sua tomada pelo poder econômico são causas da falta de credibilidade das instituições governamentais, e do seu enfraquecimento, dando margem ao surgimento de instituições políticas informais. As organizações não governamentais (ONGs) internacionais surgem como representantes de uma sociedade civil globalizada. Essas entidades têm poder e legitimidade para desencadear ações, a partir de cidadãos/indivíduos locais, de qualquer ponto do planeta, utilizando-se da mídia vertical ou horizontalizada, via ciberespaço. Segundo Virilio (1993, p. 10), "a tela tornou-se o lugar, a encruzilhada, de todos os meios de comunicação de massa", e pode-se acrescentar, a encruzilhada dos emaranhados das redes sociotécnicas, nas quais a comunicação para todos pode assumir, em certos casos, proporções massivas, até com repercussão na esfera pública internacional no espaço virtual afetando governos nacionais, regionais e locais. $O$ autor acrescenta o fator urbano na discussão das interações comunicacionais de caráter comunitário e sociopolíticos possibilitadas pelo ciberespaço, aproximando cidadãos globalizados e capacitando-os a interferir uns no território dos outros, confundindo e entralaçando o local e o mundial.

\begin{abstract}
Ninguém pode se considerar separado por obstáculo físico ou grandes 'distâncias de tempo' pois, com a interfachada dos monitores e das telas de controle, o algures começa aqui e vice-versa. [...] A partir daí o espaço construído participa de uma topologia eletrônica na qual o enquadramento do ponto de vista e a trama da imagem digital renovam a noção do setor urbano. À antiga ocultação público/privado e à diferenciação da moradia e da circulação sucede-se uma superexposição onde termina a diferenciação entre o 'próximo' e o 'distante' (VIRILIO, 1993, p. 10).
\end{abstract}

A incapacidade do Estado-Nação em gerenciar os assuntos relacionados à globalização dentro de suas próprias instâncias de governança ao encaminhá-los deliberadamente à governança internacionalizada, criando assim uma nova forma de Estado, é percebida por Castells (2008). $\mathrm{O}$ autor também evidencia que essa crise do Estado remete-o à associação com outros, criando redes de entidades supranacionais descentralizando-o e fortalecendo com poder e recursos os governos regionais e locais, as ONGs, ou seja, a sociedade civil organizada, a ágora, e o cidadão, que, por fim, está conectado à esfera pública internacionalizada.

Silverstone (2005) manifesta a presença de novas dinâmicas de transmissão, de fazer e fixação de significado com a tecnologia e novas mídias, que são mais convergentes, e propiciam uma sociabilidade interativa. 
Assim, uma nova sociedade tende a ser criada com um terceiro excluído, o Estado-Nação, e alguns elementos de uma nova retórica política surgem ao verem a tecnologia como política, por exemplo, as prefeituras e referendos contínuos e a democracia online. Lévy (1999), a seu turno, identifica a coincidência das maiores concentrações de atividades no ciberespaço com as maiores concentrações urbanas, o que ocorre concomitantemente com a desconcentração e com a 'deslocalização', sem, entretanto, eliminar os centros.

Lévy (1999) agrupa as diversas abordagens teóricas da relação entre ciberespaço e cidade em quatro categorias: analogias, substituição, assimilação e articulação. As analogias recriam no espaço virtual instituições e comunidades territoriais, transferindo para o ciberespaço suas comunicações e relacionamentos. A substituição ocupa-se da reorganização do território pela transferência de atividades, como tele-trabalho e tele-educação para o ciberespaço, que aliadas a políticas públicas, como habitacionais e de meio ambiente, minimizariam problemas. A assimilação refere-se às redes de comunicação interativas assimiladas pela infraestrutura que já urbaniza o território com ferrovias, estradas, redes de energia elétrica e de telefonia. A articulação seria uma harmonização do funcionamento urbano com a inteligência coletiva resultante do ciberespaço, ou da esfera pública de Habermas (1996), que extrapola o espaço virtual, mas cada vez mais se vale dele.

Lévy (1999) não vê benefícios sociais nas três primeiras - analogias, substituição e assimilação - porque elas mantêm as essências das desigualdades e não atingem o cerne dos problemas, apenas introduzem o fator ciberespaço no status quo vigente. $\mathrm{O}$ autor, entretanto, defende a articulação de dois fatores qualitativamente bem diferenciados - o território e a inteligência coletiva. Essa articulação seria facilitada pelo ciberespaço, onde a rigidez das instituições territoriais seria atenuada pela horizontalidade e fluidez características da comunicação na rede, o que favorece nova forma de democracia, em larga escala. A articulação levaria à eliminação das formas territoriais, dando lugar a outra mais rápida, fluida, que permitiria resolver principalmente as questões da cidade por meio de inteligência cooperativa/colaborativa/coletiva, um "utilizar o virtual para habitar melhor o território" (LÉVY, 1999, p. 196).

A organização do ciberespaço procede de uma forma particular de urbanismo ou de arquitetura, não física, cuja importância só irá crescer. Contudo, a arquitetura suprema procede do político; ela diz respeito à articulação e ao papel respectivo dos diferentes espaços. Colocar a 
inteligência coletiva no posto de comando é escolher de novo a democracia. (LÉVY, 1999, p. 196)

O ciberespaço também seria oportunidade para a imprensa recuperar seu papel dentro da esfera pública, agora internacionalizada, uma vez que as formas de interatividade com o cidadão características do jornalismo digital, a possibilidade de multiplicação das notícias pelas redes sociotécnicas e até a capacidade de interferência do cidadão na produção da notícia, estão cada vez mais potencializados pela ubiquidade da rede proporcionada pelos aparatos móveis, cada vez mais difusos e a custos cada vez mais acessíveis.

\section{Jornalismo, mobilidade e esfera pública}

As novas tecnologias utilizadas para a comunicação propiciam que os veículos de comunicação passem a produzir conteúdos personalizados e interativos para os diferentes tipos de tecnologias móveis digitais, como mobiles e tablets. As plataformas móveis, cada vez mais híbridas, aliadas ao jornalismo, promovem mudanças na prática jornalística, na dinâmica das redações e nos processos de produção de conteúdos por assumirem o papel de meio de distribuição de notícias, fortalecendo a produção colaborativa. $\mathrm{O}$ acesso à internet via rede de computadores propicia o contato com sites de conteúdo jornalístico e redes sociotécnicas, replicadoras de conteúdos das plataformas online noticiosas, visando o compartilhamento de informação e a busca de identidade com usários ao redor do globo, o que reforça a ideia de um espaço público internacional.

Para entender o jornalismo e o novo papel das redações com as mudanças tecnológicas, é preciso ter o entendimento de uma esfera pública, ou seja, conforme propõe Habermas (2003), uma esfera pública politicamente ativa, que emerge da lógica do estado burguês de direito com uma imprensa crítica aliviada pela pressão anterior da liberdade de opinião. A imprensa ativa, mediadora e potencializadora nesse processo, foi resultado do desenvolvimento da politização do público. Wolton (2004) explica que a ideia inicial do espaço público era de ampliação da esfera pública, favorecendo a informação. Hoje a ideia é reintroduzir heterogeneidade, diferenças e não aumentar a transparência, por ser um espaço de debates, valores contraditórios ou tornar-se o espaço de reificação dos valores igualitários racionalistas e democráticos. Para Humphreys (2010, p. 764), "o espaço público desempenha um papel importante em 
ambientes urbanos e pode ser um refúgio para fugir da vida citadina" e também é importante em sites de interação social. As redes sociais móveis, por exemplo, aliviam os desafios existentes para interação com os outros em público.

Gómez (2006) expõe uma perspectiva tecnocêntrica ao verificar a mudança tecnológica no contexto da sociedade do conhecimento com a democracia cibernética, pois ele vê o fortalecimento das cidadanias e desenvolvimento das democracias, sem dissolução de papéis sociais dos usuários diante da tecnologia da informação, e nem a dissolução das condições objetivas ante o conhecimento.

O relacionamento social em rede e o compartilhamento de ideias e conteúdos da mídia oportunizam aos usuários debater os problemas urbanos e hiperlocais e pôr em comum suas impressões do meio social, culturas e vivências com outras pessoas em tempo real. Martín-Barbero (2006) diz que a visualidade eletrônica passou a fazer parte constitutiva da visibilidade cultural, e essa se torna simultaneamente um meio tecnológico e novo imaginário, "capaz de falar culturalmente, de abrir novos espaços e tempos para uma nova era do sensível" (MARTíN-BARBERO, 2006, p. 74).

Nas redações americanas, conforme aponta Chainon (2008), houve mais difusão das tecnologias e os gadgets usados para capturar e transmitir dados multimídia em movimento. Assim, na prática jornalística as histórias são mais rapidamente transmitidas para a internet porque os repórteres estão mais tempo na rua. Entretanto, ele aponta a preocupação de alguns editores que demonstram temor de que essa prática possa levar a menor supervisão de conteúdo editorial.

As novas tecnologias que emergem no jornalismo exibem novos canais de colaboração e cooperação, relacionados à prática do cidadão como repórter, criando assim uma forma de diálogo diferenciada com instrumentos ancorados nos avanços dos processos comunicativos (ALVES, 2011, p. 15) e efeitos nas mudanças na forma de cobertura e práticas dos jornalistas:

As facilidades e flexibilidades proporcionadas provocaram reformulações de pensamentos e conceitos. Jornalistas encontram espaços ilimitados, facilidade de ampliar conteúdos e conhecimento, elasticidade no momento de informar e, claro, uma interação jamais vista entre o antigo consumidor de informação e um profissional de comunicação.

Essa reformulação de conceitos e praxes jornalísticas também é apontada por Silva (2009, p. 72), para o qual "a introdução de tecnologias no 
jornalismo não é nova. A novidade está no modo como se processa a informação através da capacidade de digitalização, compartilhamento, armazenamento e distribuição". Assim o processo produtivo passa a ser conectado por redes.

Um outro efeito, particularmente poderoso e em combinação com todos estes, é a emergência da mobilidade dos produtores e consumidores de informação. Nós podemos baixar da rede para dispositivos móveis sem fio o que quisermos e na hora que quisermos. Da mesma forma, podemos subir produtos que criamos enquanto estamos em movimento, em deslocamento. É uma mudança em relação à idéia de trabalho em lugar fixo (MITCHELL, 2003, p. 84 apud SILVA, 2009, p. 71, tradução nossa).

Entretanto, Moser (1996) diz que a inscrição de um desejo em que o principal sintoma é uma possível ausência de comunidade passa pelas realidades artificial e virtual e o ciberespaço. As comunidades que na visão de Silverstone (2005) são experiências conflitantes da vida social, sendo uma versão do lar - espaço político que precisa ser continuamente reiventado, que assim como a casa é depositário de memória e congnição -, mas pública e não privada e que implica sempre uma reivindicação, em razão da interação cotidiana e efervescência da ação coletiva. Os termos descritos por Moser (1996) caracterizam a problemática das comunidades virtuais e a vida social na internet, que como aponta Silverstone (2005) é uma nova era da comunidade.

\section{ComuniCode, uma experiência laboratorial}

O QR Code (Quick Responde Code) - Código de Resposta Rápida, na tradução para o português - é um codigo de barras em 2D que em contato com um telefone móvel, smartphone, é decodificado e permite que o usuário leia um texto, visualize uma imagem ou seja direcionado ao site onde o conteúdo está armazenado, com o indicativo de uma URL (Uniform Resource Locator). Esse método de comunicação por aparato tecnológico é mais utilizado na prática jornalística, ao integrar mídias com uma conexão entre o conteúdo de uma mídia impressa numa plataforma virtual, assim como em anúncios publicitários, principalmente com a popularização desse recurso nas revistas americanas.

Segundo pesquisa da ComScore, publicada em dezembro de 2011, em outubro, 20 milhões de usuários de telefone móvel nos EUA utilizaram 
um aplicativo baixado gratuitamente pela internet para ler um QR Code; $59,4 \%$ o fizeram uso do aplicativo em casa, $44 \%$ em uma loja de varejo e $21,4 \%$ no trabalho. No Brasil, essa tecnologia ainda não demonstra ser massificada. Em 2011, segundo pesquisa do International Data Corporration (IDC), o número de smartphones vendidos no Brasil cresceu $84 \%$, correspondendo a 9 milhões de unidades. Hoje, o número desses aparelhos em território nacional é de 19 milhões.

A incorporação das novas tecnologias móveis à interface jornalística facilita a aplicação dessa dimensão no conteúdo hiperlocal, e a informação transmitida pode agregar conhecimento e gerar o interesse de receptores ao redor do globo, caracterizando a inserção de assuntos hiperlocalizados no espaço público internacional. Humphreys $(2010$, p. 764$)$ cita que a conexão dos serviços com as pessoas locais "têm ido além da internet para o telefone móvel ou celular". A partir disso, "a acessibilidade e mobilidade deste dispositivo sugerem que as pessoas podem usar esses serviços para se conectar com as pessoas locais em tempo real à medida que avançam pelas cidades" (HUMPHREYS, 2010, p. 764). Hall (2006) expõe uma tendência em direção à homogeneização global, e com isso surge o interesse pelo local, que atua no interior da lógica da globalização. Para ele, a globalização não vai destruir as identidades nacionais criadas, mas "produzir, simultaneamente, novas identificações 'globais' e novas identificações 'locais'" (HALL, 2006, p. 77-78). A vida urbana e as cidades revelam traços culturais distintos, com características heterogêneas e onde se desenvolvem relações sociais fortes e a vida social se faz presente.

Nesse processo, Lemos (2007) expõe o papel tecnológico e da vinculação com o espaço local pelas mídias locativas, um "conjunto de tecnologias e processos info-comunicacionais cujo conteúdo informacional vincula-se a um lugar em específico" (LEMOS, 2007, p. 1). Elas se caracterizam como "dispositivos informacionais digitais cujo conteúdo está diretamente ligado a uma localidade" (LEMOS, 2007, p. 1) e agregam, inclusive, conteúdo digital a uma localidade, com o auxílio, por exemplo, de telefones celulares para esse processo. Assim "os lugares/objetos passam a dialogar com dispositivos informacionais, enviando, coletando e processando dados a partir de uma relação estreita entre informação digital, localização e artefatos digitais móveis" (LEMOS, 2007, p. 2).

Ao estudarem alguns desses assuntos e tomarem conhecimento da existência do QR Code, os alunos da disciplina "Jornalismo e Novas Mídias" da Pontifícia Universidade Católica do Paraná (PUCPR) receberam um desafio do professor: encontrar alguma forma de utilizar o código em produtos jornalísticos. Iniciou-se imediatamente um processo 
de brainstorming sobre possibilidades. A discussão continuou em fórum online no ambiente virtual do sistema Eureka, e culminou em sala de aula, onde se decidiu, por votação, produzir um jornal digital multimídia, com distribuição via QR Code e leitura em smartphones 3G.

A turma inspirou-se no jornal laboratório impresso do curso, o Comunicare, cujas edições dedicam-se, cada uma, a explorar por diferentes abordagens jornalísticas determinado tema geral. Esse exercício jornalístico, ao longo dos 16 anos de existência do Comunicare, tem se mostrado bastante eficiente no ensino do jornalismo, e tem rendido ao jornal reconhecimento comprovado pelos diversos prêmios conquistados.

Dada a semelhança de ser temático, o novo veículo multimídia foi batizado de ComuniCode, um Comunicare digital, multimídia e que usaria o QR Code como forma de acesso. Essa escolha também deu-se por votação, após serem apresentadas várias propostas de nomes. Brainstorming seguido de votação foi o processo de escolha do tema.

Entre os diversos temas sugeridos, o escolhido foi o Edifício Asa, um prédio antigo e tradicional do Centro de Curitiba, cujas características ofereceriam muitas possibilidades de pautas interessantes, assim como possibilidades de produções de matérias em diferentes mídias.

Decidiu-se que o ComuniCode seria apresentado aos leitores/receptores em exposições no hall de alguns dos blocos da PUCPR, Câmpus Curitiba, no período noturno, quando há grande afluxo de pessoas. Seriam usados tapumes nos quais se fixariam os códigos QR de todas as matérias, impressos em tamanho relativamente grande, acompanhados das manchetes/chamadas das respectivas matérias. Os alunos da turma estariam perto dos tapumes explicando aos transeuntes como acessar as notícias e poderiam até emprestar seus aparelhos celulares para a visualização, caso o leitor/receptor não tivesse celular 3G no momento. Os alunos também estariam a postos para instruir aqueles que desejassem baixar nos seus celulares algum aplicativo que possibilitasse o acesso aos códigos QR.

Posteriormente, os alunos da turma dividiram-se em cinco editorias: Economia, Cultura/Educação, Comportamento, Geral e Saúde/Esporte. Cada editoria escolheu um editor responsável e a turma escolheu um editor-chefe. As aulas, a partir de então, transformaram-se em encontros de trabalho entre o professor orientador e o editor-chefe com as editorias. Cada editoria tinha um horário marcado com eles; e esporadicamente eram feitas reuniões somente entre os editores, o professor e o editor-chefe, a quem coube organizar um blog no qual as matérias seriam postadas, uma vez que o QR Code demanda um suporte online, que pode ser site ou blog. 
A primeira etapa de produção de conteúdos para o QR teve caráter exploratório. A tarefa da primeira semana para todas as equipes foi visitar o Edifício Asa, de forma discreta, para a prospecção de pautas para a sua respectiva editoria. No dia de aula, a editoria discutiria as possíveis pautas com o professor e com o editor-chefe. Seguiu-se uma reunião entre os editores para delimitar as fronteiras de cada editoria e evitar sobreposição de assuntos.

Na segunda etapa, cada editoria discutiu internamente suas pautas e definiu quais seriam produzidas. Após essa decisão, as editorias analisaram as características da notícia e estudaram qual seria a melhor mídia para apresentá-la ao receptor. Da mesma forma que na etapa anterior, cada editoria reuniu-se com o professor e editor-chefe para debater as pautas e mídias propostas.

A terceira etapa foi a de produção das matérias. Cada editoria produziu, em média, três pautas, cada uma utilizando mídia diferente. A meta era produzir uma matéria por semana, discuti-la com o professor e o editor-chefe, fazer as correções necessárias e proceder à produção seguinte. Assim foi feito, até que se chegou à fase seguinte, que chamaremos de "montagem", na qual o editor-chefe e dois alunos auxiliares montaram o blog, contendo as produções em texto, fotografia, áudio, vídeo e infografia.

A quinta etapa ocorreu coletivamente, com toda a turma em sala de aula, e envolveu a produção das manchetes/chamadas do jornal. Optouse pelas chamadas tendendo ao factual, buscando-se a informação mais chamativa, que despertasse maior curiosidade do leitor e que já passasse a informação principal. Todas as matérias produzidas seriam chamadas.

A sexta etapa realizou-se, como previsto, com a exposição dos $Q R$ Codes no hall de alguns blocos da universidade, quando os transeuntes, instruídos pelos alunos produtores do ComuniCode, puderam acessar as matérias sobre o Edifício Asa, em diversas mídias, usando aparelhos celulares.

\section{Considerações finais}

Ao contrário do que se pressupunha quando o jornalismo começou a ser difundido pela internet nos anos 1990, os grandes portais de notícias não são, em termos relativos, hegemônicos quando se trata de audiência, ou, usando-se linguagem mais específica, em número de acessos. A hegemonia cabe aos sites dedicados às notícias locais e, mais ainda, hiperlocais. 
Caminho oposto segue a esfera pública. Assuntos locais ou mesmo hiperlocais podem ser deliberados, graças à rede mundial de computadores, por cidadãos conectados de qualquer ponto do planeta, subvertendo a noção de território, criando espécie de territorialidade estendida, que abarca virtualmente seus cidadãos onde quer que estejam.

Por outro lado, também a noção de cidadania se descola dos limites territoriais quando um indivíduo de qualquer nacionalidade interfere, também de qualquer local, virtualmente, em questões políticas nacionais, regionais, locais ou mesmo hiperlocais. Essa "cidadania aumentada" reforça a existência de uma esfera pública internacionalizada no ciberespaço, na qual, tudo indica, a imprensa, agora digital, recupera sua importância no espaço público. A mobilidade da recepção midiática e da interatividade do leitor-receptor permite que ele se torne gatekeeper na difusão de notícias via redes sociotécnicas, comentarista e analista das notícias publicadas também via redes ou por mecanismos proporcionados pelos próprios veículos digitais, e colaborador na produção de conteúdos jornalísticos, fazendo com que a imprensa se torne mais cidadã, e que seu alcance seja ilimitado em termos geográficos. Essa nova realidade comunicacional e territorial torna possível a coexistência de um aparente paradoxo: o receptor está cada vez mais interessado no jornalismo local e hiperlocal, porém está inserido em uma esfera pública internacional, podendo atuar tanto numa quanto em outra, de onde quer que esteja em tempo real ou escolhido.

As tecnologias da informação e comunicação (TICs) ancoradas por ferramentas jornalísticas propiciam novas formas de conhecimento e diferentes formas de apropriação do conteúdo. Os grandes produtores de informação precisam segmentar seus conteúdos em formatos capazes de se adequar às exigências e personalização dos diferentes públicos. No mesmo passo, a democracia cibernética constitui novos elementos para a busca da cidadania e construção de uma esfera política, entre eles a instituição de laços colaborativos e cooperativos com a agregação de heterogeneidade e diferenças que propiciam o amálgama de ideias em prol de objetivos comuns e interesse partilhado.

\section{Referências}

ALVES, R. S. S. Minha notícia, iReport e OhmyNews: modelos de cooperação ou colaboração no Jornalismo Digital? In: JUNIOR, W. T. L. Comunicação, tecnologia e cultura de rede. São Paulo: Momento Editorial, 2011. p. 12-39. 
CASTELLS, M. The new public sphere: global civil society, communication networks, and global governance. The Annals of the American Academy of Political and Social Science, v. 616, p. 78-93, Mar. 2008.

CENTRO DE ESTUDOS SOBRE AS TECNOLIGIAS DA INFORMAÇÃO E DA COMUNICAÇÃO - CETIC. TIC 2010: domicílios e empresas - pesquisa sobre o uso das tecnologias de informação e comunicação no Brasil. Disponível em: <http://op.ceptro.br/ cgi-bin/indicadores-cgibr 2010?pais=brasil\&estado=pr\&academia=academia\&age= de-25-a-34-anos\&education=pos-mestrado\&purpose=pesquisa-academica $>$. Acesso em: 8 abr. 2012.

CHAINON, J. Y. US: Mobile journalism is changing the newsroom. 2008. Disponível em: <http://www.editorsweblog.org/2008/05/21/us-mobile-journalism-is-changing-the-newsroom>. Acesso em: 12 abr. 2012.

COMSCORE DATA MINE. 20 Million Americans Scanned a QR Code in October. 2011. Disponível em: <http://www.comscoredatamine.com/2011/12/20-million-americans-scanned-a-qr-code-in-october/>. Acesso em: 9 abr. 2012.

EGLER, T. T. C. Redes sociotécnicas, políticas públicas e gestão democrática da cidade. In: EGLER, T. T. C. (Org.). Ciberpólis: redes no governo das cidades. Rio de Janeiro: 7 Letras, 2007. p. 7-22.

GÓMEZ, G. O. Comunicação Social e mudança tecnológica: um cenário de múltiplos desordenamentos. In: MORAES, D. Sociedade midiatizada. Rio de Janeiro: Editora Mauad, 2006.

HABERMAS, J. Between facts and norms: contributions to a discourse theory of law and democracy. Cambridge: MIT Press, 1996.

HABERMAS, J. Mudança estrutural da esfera pública: investigações quanto a uma categoria da sociedade burguesa. Rio de Janeiro: Tempo Brasileiro, 2003.

HALL, S. A identidade cultural da pós-modernidade. Rio de Janeiro: DP\&A, 2006.

HUMPHREYS, L. Mobile social networks and urban public space. New Media \& Society, v. 12, n. 5, Aug. 2010. Disponível em: <http://nms.sagepub.com/content/12/5/763>. Acesso em: 8 abr. 2012.

KAUCHAKJE, S. et al. Redes socio-técnicas y participación ciudadana: propuestas conceptuales y analíticas para el uso de las TICs. REDES - Revista hispana para el analisis de redes sociales, v. 11, n. 3, dec. 2006. Disponível em: <http://revistes.uab. cat/redes/article/view/88/89>. Acesso em: 23 jul. 2013. 
LEMOS, A. Mídia locativa e territórios informacionais. Disponível em: <http://www.facom.ufba.br/ciberpesquisa/andrelemos/midia_locativa.pdf>. Acesso em: 12 abr. 2012.

LÉVY, P. Cibercultura. Rio de Janeiro: Editora 34, 1999.

MARTÍN-BARBERO, J. Tecnicidades, identidades, alteridades: mudanças e opacidades da comunicação no novo século. In: MORAES, D. Sociedade midiatizada. Rio de Janeiro: Editora Mauad, 2006.

MOSER, M. A. Immersed in technology: art and virtual environments. Cambridge: MIT Press, 1996.

SILVA, F. F. Tecnologias móveis como plataformas de produção no jornalismo. In: LEMOS, A. (Org.). Comunicação e mobilidade: aspectos socioculturais das tecnologias móveis no Brasil. Salvador: EDUFBA, 2009.

SILVERSTONE, R. Por que estudar a mídia?. São Paulo: Loyola, 2005.

VIRILIO, P. O espaço crítico e as perspectivas do tempo real. Rio de Janeiro: Editora 34, 1993.

WOLTON, D. Pensar a comunicação. Brasília: Ed. UnB, 2004.

Recebido: $12 / 06 / 2013$

Received: 06/12/2013

Aprovado: $25 / 06 / 2013$

Approved: 06/25/2013 